\title{
Calligraphy Treatment of Children with ADHD: A Case Study
}

\author{
Henry SR Kao1*, Chiu Sau Mee ${ }^{2}, \mathrm{Hu} \mathrm{Bin}^{3}$ and Yushi Jiang \\ ${ }^{1}$ Department of Psychology University of Hong Kong, China \\ ${ }^{2}$ Alliant International University, San Francisco \\ ${ }^{3}$ Haidian Special School for Mental Retardation, Beijing \\ ${ }^{4}$ Yishuge gGmbH, Berlin
}

*Corresponding author: Henry SR Kao, Department of Psychology University of Hong Kong, China

\section{Introduction}

Chinese calligraphic handwriting (CCH) entails an integration of the mind, body, and character, interwoven in a dynamic process of handwriting. It involves visual perception of the character, spatial structuring of the character, cognitive planning, and maneuvering of the brush to follow specific character configurations Chen L [1]. In addition, long-term $\mathrm{CCH}$ training facilitates and improves the practitioner's specific executive functions as well as the strengthening their neural networks in related brain regions Chen W et al. [2]. More specifically, the latest fMRI studies have further established the CCH's capability of improving the practitioner's selective attention and divided attention Chen $\mathrm{W}$ et al. [3]. These works have provided theoretical foundations for the efficacy of the CCH therapy. It has been, in recent years, gradually established as an indigenous and complementary practice that is capable of improving people's behavioral, psychosomatic as well as clinical conditions. These include attention and concentration as well as the facilitation of their physical relaxation and emotional stabilization Kao HSR \& Kao HSR [4,5].

Successful treatments with this intervention have been obtained with patients of Alzheimer's disease, PTSD, dementia, as well as childhood disorders of autism and ADHD. These treatment effects were elicited by the CCH training, which entails an integration of the mind, body, and character, interwoven in a dynamic feedback process. The conceptual framework for calligraphy treatment is threefold. First is the sensory feedback: the individual receives sensory feedback from the graphic record while writing calligraphy. Second is the bio-emotional feedback, involving the movement of the arms and the whole body as the individual guides and regulates his movement. Finally, the cognitive feedback: the subjective experiences of heighted attention, alertness, and faster responses during the writing acts Studies on CCH have confirmed its positive effects on visual alertness, cognitive activation, emotional stability as well as physiological quiescence and relaxation Kao HSR \& Kao
HSR [4,5]. The disorders studied have included, among others, attention-deficit/ hyperactivity Chen CC et al. [6], and mental retardation $\mathrm{Hu} \mathrm{B}$ et al. [7], as well as autism Lai SF et al. [8]. The positive and facilitative effect of the $\mathrm{CCH}$ is well documented for modifying, modulating and changing behaviors in normal as well as disordered children.

\section{Present study}

The aim of the present study was to analyse the efficacy of the $\mathrm{CCH}$ training as an effective treatment in improving interpersonal relations, social behaviour, negative activities and speech communication that are associated with the ADHD children. We adopted the in-depth qualitative approach of case studies to examine specific psychological changes, likely decrease of disruptive behaviours as well as reduced clinical symptoms in children with the ADHD. We conducted a case study with a view to assessing the effects of Chinese calligraphy therapy on a child diagnosed with ADHD and his primary career, his mother. It is expected that the research may shed light on the details of the treatment plan such as therapy administration, the follow up actions, and on-site implementation of the training to sustain the therapy, as well as other relevant consideration factors such as family therapy.

\section{Method \\ Participants}

A child, aged 7, diagnosed with ADHD, and his mother who was aged 46 and the child's primary career took part in the case study. The child came from a family with father, an English man, mother of ethnic Chinese, and an elder brother aged 9.

\section{Measures}

In order to evaluate the effect of the treatment on the child, the following measures were used and completed by the mother of the child: 
a) Disturbing Behavior Inventory (DBI) of the Child.

b) Beck Anxiety Inventory (BAI).

\section{Procedures}

The participants were given a special set of four booklets containing Chinese calligraphy templates (Kao \& Lam, 2007). The child and his mother used Chinese brush pens to write on five pages of Chinese calligraphy templates everyday from Monday to Friday for four weeks. Thus, each of them had to complete a total of 100 pages (i.e. 5 pages $x 5$ days $x 4$ weeks) of writings. The participants were briefed to take time in writing the calligraphy and preferably to use around 30 minutes to complete the writing every day. In order to facilitate the assessment of the effects of the therapy, the mother of the child had to complete the following questionnaires before and after the therapy: the

a) Disturbing Behavior Inventory (DBI).

b) Beck Anxiety Inventory (BAI).

Moreover, the mother was interviewed by the researcher before and after the 4-week therapy. While the mother would take part in the therapy herself, she would write the calligraphy together with the child, with the whole process video recorded.

\section{Results}

\section{The child}

Before the 4-week therapy, the child was reported by his mother as very active and could not keep doing a task non-stopping for a few minutes. The child was slow in writing and often requested for many breaks and time-outs in doing his homework. The child was observed to have a pattern of leaving his seat or changing his sitting postures every 7-8 minutes. However, his impulsivity was within the manageable level, as little socially inappropriate behavior was observed. Week one: the child showed great curiosity and interests in the writing. He asked many questions throughout the writing, just like writing which word first, whether he should write faster or not, and how to dry the writing, etc. The child was also observed to be very energetic and of high mood, especially when he noticed that he was being videoed. He showed smiling faces in front of the camera and initiated different topics to talk with his mother. When his mother praised him for writing well and encouraged him to talk less but concentrate on writing, the child stop talking for a while but resumed talking after 1 minute. Week two: the child found the writing more difficult than that of previous weeks. He did request to stop writing or do only the easy ones. The child also needed about 30 minutes to do the writing. However, when his mother kept accompanying and encouraging him to write, he was able to do the tasks. The writing appeared to be good and positive experiences for the child. He accepted the difficult tasks with tenacity. He became delighted when he realized that the writing templates were less sophisticated for the following week.

Week three, the child did show enthusiasm in taking part in the calligraphy therapy. He sometimes reminded his mother that they should do the writing, showing his good sense of responsibility.
According to the mother, the child appeared to enjoy being video recorded. He also tended to complete the writing fast, especially when he worried that his mother was writing faster than him. However, when his mother reminded him to slow down and keep concentrate on writing, he started slowing down a bit. However, he became writing faster if his mother stopped reminding him to slow down. Week four, the child indicated that he did not wish to stop writing the Chinese calligraphy after the fourth week, as he found this activity interesting. He also indicated that it was easy and indeed enjoyable for him to complete the writing in the fourth week. The mother needed sometime to help the child process the termination of the 4-week calligraphy therapy. At the end, the child was looking forward to having another round of therapy soon.

Post therapy assessment on the Disturbing Behavior Index (DBI) revealed significant decrease in the following behaviors:

a) Difficult in maintaining attention at work or play.

b) Leaving seat without permission while in classroom or when sitting was required.

c) Taking part in recreational or interesting tasks quietly.

d) Difficult in handling tasks and activities systematically.

e) Talk too much.

f) Rush to answer even when the questions were not fully spoken out.

g) Interrupt or disturb the others.

h) Causing difficulties in learning self-care.

i) Causing difficulties in play, relaxation and recreation.

j) Causing difficulties in dealing with daily activities or other duties.

k) Actively resist or decline obeying adult's request or regulation.

l) Being angry or frustrated.

m) However, the following behavior of the child was observed to have increased after the therapy.

n) Being forgettable in daily life.

o) Causing difficulties in interacting with other children.

p) Argue with the adults.

q) Deliberately provoking others' anger.

\section{The mother}

The mother's behavior throughout the 4-week training was relatively stable and consistent as compared to that of her child. As the total score of BAI, it was noted that the mother had lower anxiety score (from 9 to 6 ).

The pre and post assessment revealed that the mother reported less anxiety index of in the following areas:

a) Feeling heated. 
b) Not very concentrated.

c) Indigestion problems.

During the post therapy interview, the mother stated that she really found the Chinese calligraphy therapy worked as when she was very upset or emotional, she would then go into her room and start writing the calligraphy practice alone. She would then become calm and less stressful. She also felt good when she did assign a particular time slot to do something interesting with her child on a daily basis. She realized that her relationship with her child became more positive. Subjectively, the mother did find practicing Chinese calligraphy writing would help her stabilize her emotions and free her from the overwhelming negative thoughts during her low stage of work life.

\section{Discussion}

The findings from this in-depth case analysis serve to corroborate both the theoretical expectations and the previous researches over the effects of $\mathrm{CCH}$ treatments in general as well as specific similar activities reported in other studies dealing with childhood behavioral disorders, including autism, ADHD, and mental deficiency. These are especially significant in that very detailed changes of behavior activities on the part of the child were observed and described at this level of scrutiny. Of particular interest in this case analysis is the finding for the first time a parent's presence and co-participation with shared tasks of brush handwriting has also resulted in a carer's psycho-emotional stability and benefits. This points to the prospect of examining the efficacy of an onsite parent-child social co-training as a viable option of application. Here are below our reviews of some training experience arising from this case study.

\section{The research perspective}

The results of the 4-week calligraphy therapy are positive in most of the areas including less disturbing behaviors of the child and lower anxiety of the mother. Apart from the quantitative evidence, this research adopted a qualitative approach by indepth examination of the effects of the therapy. It was noted that such qualitative research was very useful and provided greater understanding of the specific causal effects of behavior changes in the course of the therapy. Apart from the qualitative research, it would be advised to conduct follow-up studies on the long- term effects of this calligraphy therapy in the areas of specific cognitive, emotional and behavioral changes. On considering the high predictability of early behavioral problems and the hyperactivityimpulsivity issues towards later criminal involvement, it would be advised to introduce early therapy to assure sustainable positive effects in the long run.

The therapy administration perspective According to the indepth interview, it was noted that Chinese calligraphy therapy was relatively easy to administer. Unlike pharmacological treatment, individual or group psychotherapy, the child could practice the calligraphy writings at a time and a place of his/her most convenience. From the experience of this study, it would be advisable to have a room or at least a corner set aside for the therapy, so that the brush pen, ink, paper and templates would be all ready for the child's ready. This would definitely facilitate the child to take part and enjoy the writings, as the child needed to do the writing for 30 minutes a day, five days a week, continuously for four weeks. Special care should be made to arrange a suitable environment to conduct the therapy, free from other distractions like noise, visual or social stimuli.

\section{The therapeutic approach perspective}

Originally, the child with ADHD was the primary client of this case study. However, it was later found that the carer of the child, i.e. the mother, also benefited greatly from the therapy in terms of anxiety coping, stress management, and mother-child relationships. Further research might consider the possibility of conducting calligraphy training from the perspective of the family therapy approach. From the experience of this case study, it might be a good idea for the other members of the family including the father (an English man) and the eldest brother to join the child and the mother for the practice at the same time. Turning such a therapy as family activities may help them to share common interesting experiences and learn how to be calm and relaxed together. Even not for a family therapy, it would be helpful to turn the individual therapy as a parent-child therapy to ensure the positive companion effect of the therapy.

\section{Acknowledgement}

We thank Tin Tin Kao and Stewart P. W. Lam of the University of Hong Kong for help in the preparation of this article.

\section{References}

1. Chen L (1982) Topological structure in visual perception. Science 218(4573): 699-700.

2. Chen W, He Y, Gao Y,Zhang CP, Chen CS, et al. (2017) Long-Term Experience of Chinese Calligraphic Handwriting Is Associated with Better Executive Functions and Stronger Resting-State Functional Connectivity in Related Brain Regions. PLoS One 12(1): e170660.

3. Chen W, Chen C, Yang P, Bi S, Liu J, et al. (2019) Long-term Chinese calligraphic handwriting reshapes the posterior cingulate cortex: A VBM study. PLoS ONE 14(4): e0214917.

4. Kao HSR (2006) Chinese calligraphic handwriting (CCH): a science for health and behavioural therapy. International Journal of Psychology 41(4): 282-286.

5. Kao HSR (2010) Calligraphy therapy: A complementary approach to psychotherapy, Asia Pacific Journal of Counselling and Psychotherapy 1(1): 55-66.

6. Kao HSR, Chen CC, Chang TM (1997) The effect of calligraphy practice on character recognition reaction time among children with ADHD disorder. In: Proceedings of the $55^{\text {th }}$ Annual Convention of the Council of Psychologists pp: 45-49.

7. Kao HSR, Hu B, Zhang B (2000d) Effects of Chinese calligraphic handwriting on reasoning, executive abilities and psychological health of children with mild mental retardation. In: Kao HSR (Edt.), Chinese calligraphic therapy. Hong Kong University Press, China pp: 321-344.

8. Kao HSR, Lai SF, Fok WY, Gao DG, Ma TH (2000e) Brush handwriting treatment of negative behaviours in school and at home in children with autism. In: Book of Abstracts, $8^{\text {th }}$ Glasgow, Autism-Europe Congress. China pp: 19-21. 
(c) (P)

This work is licensed under Creative Commons Attribution 4.0 License

To Submit Your Article Click Here:

Submit Article

DOI: 10.32474/OAJCAM.2019.01.000127

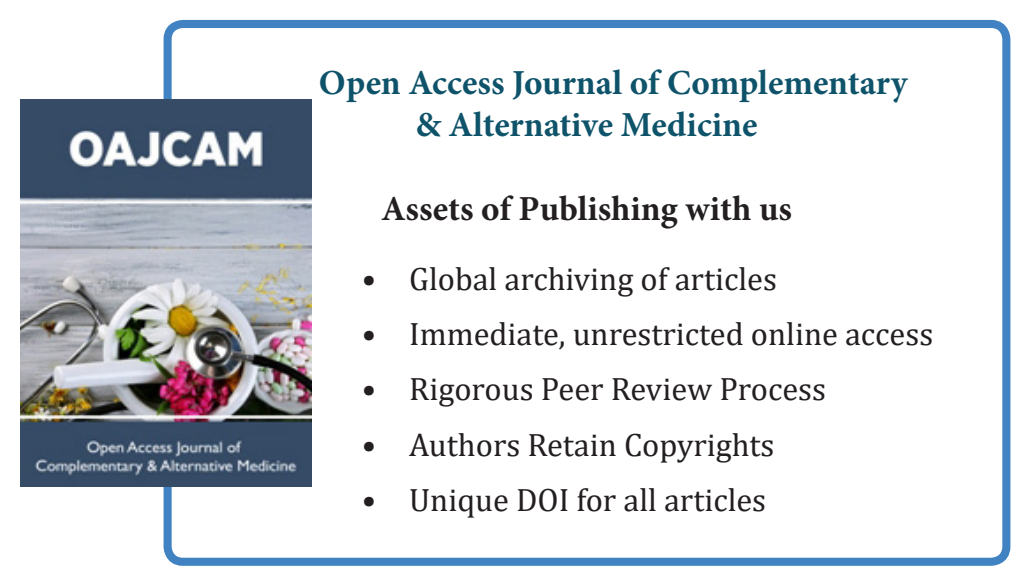

